\title{
The effect of ischaemia on nerve conduction in the carpal tunnel syndrome
}

\author{
PAMELA M. FULLERTON \\ From the National Hospital, Queen Square, and the Middlesex Hospital, London
}

It is now generally accepted that the carpal tunnel syndrome is caused by a lesion of the median nerve at the wrist under the flexor retinaculum. The site of the lesion has been established by clinical observations; for example, a local abnormality of the nerve just above or under the retinaculum is seen at operation in many patients, and, even in those in whom the nerve appears normal, attacks of pain and paraesthesiae are permanently relieved by division of the retinaculum (Kremer, Gilliatt, Golding, and Wilson, 1953). Furthermore, electrophysiological studies have demonstrated abnormalities of motor and sensory nerve conduction below the wrist in these patients (Simpson, 1956; Gilliatt and Sears, 1958). The mechanism by which the symptoms are produced, however, remains uncertain. Thus, there is still considerable doubt as to the relative importance of direct pressure on the nerve and of ischaemia due to interference with its blood supply. The fluctuating nature of the symptoms in many patients suggests that vascular factors may be important and this possibility has been discussed by various authors (e.g., Brain, Wright, and Wilkinson, 1947; Kremer et al., 1953; Kendall, 1960).

Gilliatt and Wilson $(1953,1954)$ have demonstrated that the median nerve of many patients with the carpal tunnel syndrome is abnormally susceptible to ischaemia. They studied sensory changes in the hand after a pneumatic cuff had been inflated round the arm to above arterial pressure. In some patients intense paraesthesiae in the fingers supplied by the median nerve developed within three minutes of the onset of ischaemia, accompanied by pain in the hand which often spread up the arm. Mild paraesthesiae occurred in normal subjects, but in the carpal tunnel patients they were more intense and predominantly median in distribution. Patients described the symptoms occurring during ischaemia as being similar to those experienced in their spontaneous attacks; this supports the suggestion that spontaneous attacks are caused by ischaemia. Gilliatt and Wilson (1954) also found that during ischaemia loss of sensation in the fingers supplied by the median nerve occurred earlier in patients with the carpal tunnel syndrome than in control subjects. These observations, however, depended on subjective changes reported by the patients. Nerve conduction may be studied objectively by electrophysiological techniques and the present work is based on the study of conduction in motor fibres of the median nerve during ischaemia. By correlating this with clinical and other electrophysiological abnormalities in patients with the carpal tunnel syndrome further information about the mechanism of production of symptoms and abnormal conduction in the damaged nerve fibres has been obtained.

\section{METHODS}

At the beginning of each examination the course of the median nerve was plotted by electrical-stimulation through the skin. Points abut $2 \mathrm{~cm}$. proximal to the wrist crease and $2 \mathrm{~cm}$. distal to the elbow crease were marked where twitches of the thenar muscles were most easily produced by nerve stimulation. These were the subsequent sites of cathodal stimulation (Fig. 1). An anode was placed $3 \mathrm{~cm}$. proximal to the cathode at each level of the arm. The stimulating electrodes were silver discs $1 \mathrm{~cm}$. in diameter, held firmly in place over the course of the nerve. Single shocks were delivered to the median nerve at two or five-minute intervals during



FIG. 1. Diagram of electrode arrangement. 
ischaemia, the stimulus being a condenser discharge (time constant $150 \mu \mathrm{sec}$.) which was delivered through an isolating transformer (output impedance $1,000 \mathrm{ohms}$ ). Stimulus voltage was continuously variable up to 300 volts and was adjusted to be supramaximal for motor fibres at the beginning of each examination. However, the electrical threshold of a nerve trunk, after an initial fall, is known to rise during ischaemia (Kugelberg, 1944); when, therefore, the muscle action potential began to decrease the stimulus intensity was increased to ensure that it remained adequate for fibres that were still capable of conducting impulses.

The thenar muscle action potential was recorded through silver disc electrodes $1 \mathrm{~cm}$. in diameter. One electrode was firmly fixed over the most prominent part of the belly of the abductor pollicis brevis and a second at the base of the index finger. Recordings were also made from the hypothenar muscles to ensure that the ulnar nerve was not excited by spread of current from the cathode over the median nerve. The subject was earthed through a silver plate 2.5 by $5 \mathrm{~cm}$. attached to the dorsum of the hand. After the electrodes had been fixed in position the hand and forearm were firmly bandaged to a splint.

Muscle action potentials were amplified by conventional RC coupled amplifiers with time constants of approximately 100 milliseconds and high frequency responses which were not reduced by more than $3 \mathrm{db}$ at 7,000 c/s. The action potentials were displayed on one beam of a double-beam cathode ray oscilloscope. The second beam provided a time scale.

The stimulus was locked to a fixed point on the sweep and the latency of the muscle response was measured from the stimulus artefact to the first deflection of the action potential. The action potential usually took the form of a simple biphasic wave and its size was estimated by measuring both amplitude and area. Amplitude was assessed by measuring the vertical distance between the peaks of the biphasic wave, and area was measured with an electronic integrator. The results during ischaemia were expressed as percentages of the values recorded when the nerve was stimulated immediately after inflating the cuff. In one subject a long polyphasic action potential was recorded instead of the more usual biphasic wave. For a dispersed polyphasic response of long duration measurements of amplitude and area are of doubtful significance. The results in this case are therefore considered separately.

The subjects, lying on a couch and covered with a blanket, were examined in a warm room. The arm was warmed in hot water for about $\mathbf{1 0}$ minutes before applying the electrodes. During the test it was wrapped in several layers of cottonwool. Skin temperature was recorded from the thenar eminence and initially was between 34 and $36^{\circ} \mathrm{C}$. During a 30 -minute period of ischaemia the temperature fell between one and two degrees Centigrade.

Ischaemia was produced by rapidly inflating a 6 in. wide pneumatic cuff round the upper arm to above arterial pressure and maintaining it at 200 to $220 \mathrm{~mm}$. $\mathrm{Hg}$.

To ensure that there was no change in the muscle action potential in the absence of ischaemia some subjects were examined with no cuff round the arm. The median nerve was stimulated at the wrist and elbow at five-minute intervals for an hour. Action potential amplitude and area varied by not more than $\pm 5 \%$ during this time.

\section{EFFECTS OF ISCHAEMIA ON SIZE OF ACTION POTENTIAL}

CONTROL SUBJECTS Observations were made in 10 control subjects. These were healthy subjects or patients without any clinical abnormality of the peripheral nerves in the arm tested. Their ages ranged from 25 to 65 years.

In each case a pneumatic cuff round the upper arm was inflated to above arterial pressure for $\mathbf{3 0}$ minutes. The thenar muscle action potentials evoked by single stimuli applied intermittently to the median nerve at the wrist were recorded in all subjects and the responses to stimulation at the elbow also in five of the subjects.

Wrist stimulation Figure 2 shows graphically the effects of 30-minute periods of ischaemia on the amplitude and area of the muscle action potentials in the 10 control subjects when the median nerve was stimulated at the wrist. A comparison of theo two graphs shows that the results obtained by mea suring amplitude and area were similar. An illu疋
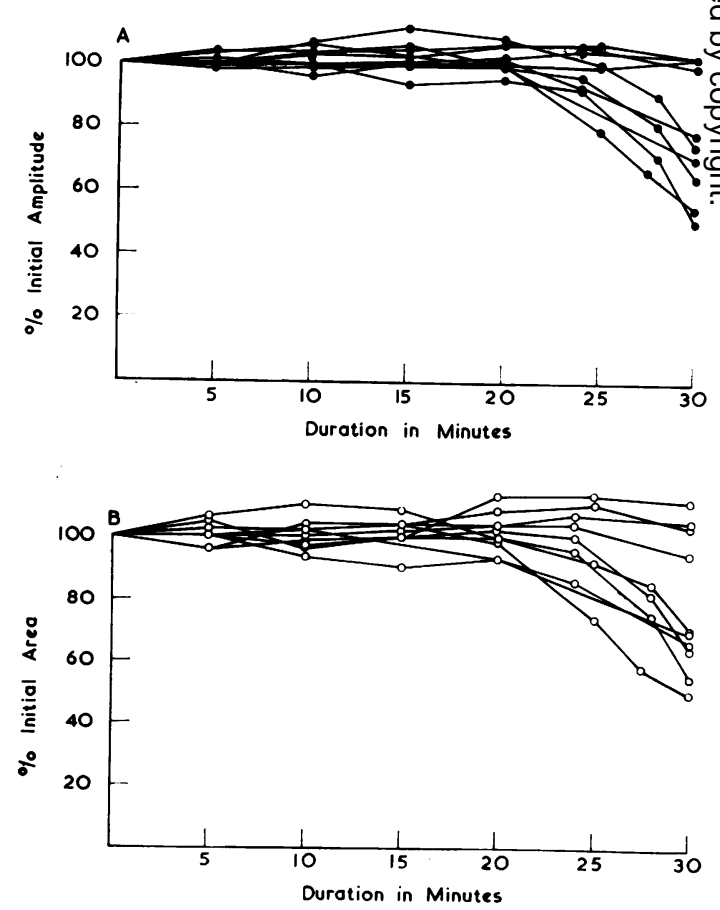

FIG. 2. Graphs showing the effects of 30 minutes' ischaemia on the amplitude and area of the thenar muscle action potentials in 10 control subjects. Stimulation at wrist. 

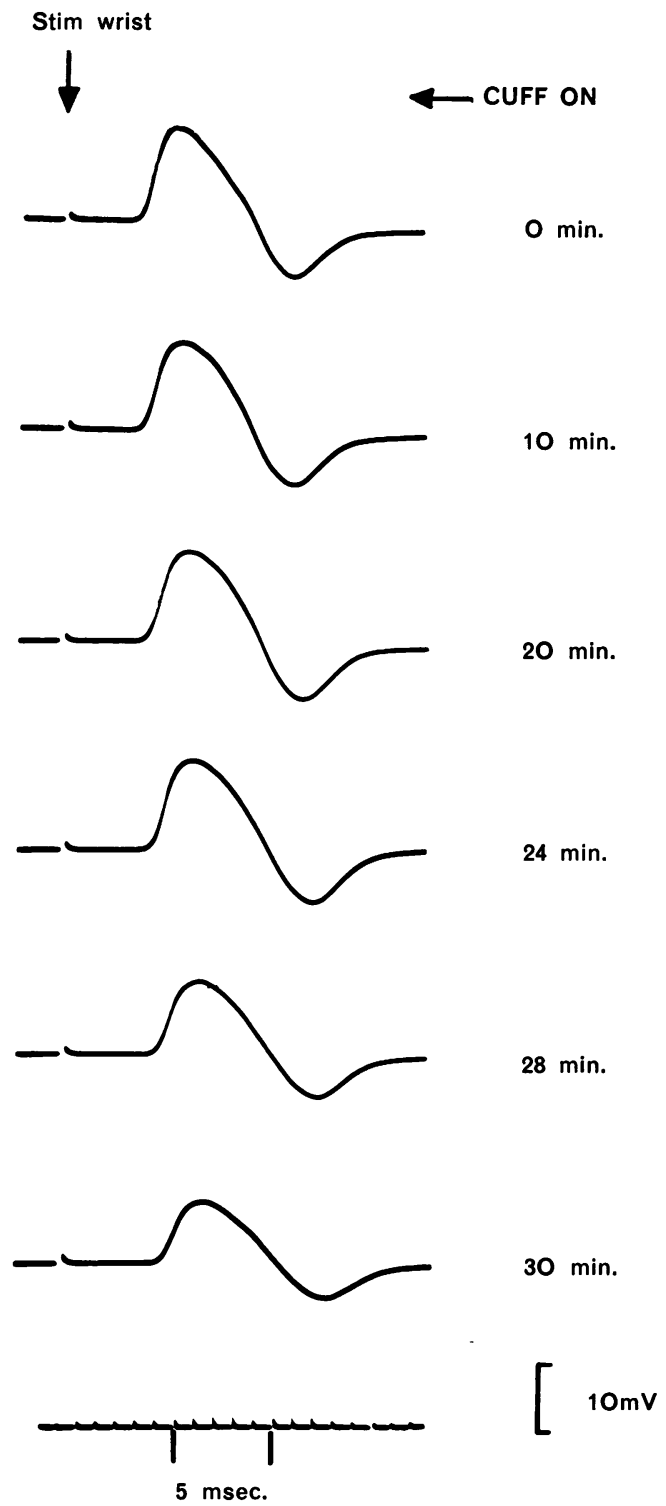

FIG. 3. Photographic records of the thenar muscle action potentials during 30 minutes' ischaemia in a control subject.

strative record is shown in Fig. 3. There was no significant change in the size of the action potential after 20 minutes' ischaemia in any of the control subjects. After 25 minutes amplitude and area were still more than $70 \%$ of their initial size in all subjects. After 30 minutes' ischaemia there was some decrease in the size of the action potential in six subjects. In all cases, however, amplitude and area were at least $50 \%$ of their initial value at the end of 30 minutes.
The susceptibility of the nerve fibres to ischaemia bore no relation to the age of the subjects.

Elbow stimulation In control subjects the action potential evoked by stimulation of the median nerve at the elbow always decreased in size before any change was seen with stimulation of the nerve at the wrist. Figure 4 shows the amplitude of the muscle action potentials following wrist and elbow stimulation in five of the control subjects. It can be seen that the action potential following elbow stimulation began to decrease between 10 and 18 minutes after the onset of ischaemia and that no potential was recorded in any of the control subjects by the end of 30 minutes' ischaemia. Similar findings in normal subjects have been reported by Magladery, McDougal, and Stoll (1950).

Nerve fibre threshold During a period of ischaemia nerve fibre threshold falls initially and then gradually rises (Kugelberg, 1944). Figure 5a shows the results obtained during one experiment in which stimulus intensity/response curves were recorded during ischaemia. Stimuli of increasing intensity were applied at five-second intervals immediately after inflating the cuff and again after 10,20, and 30 minutes of ischaemia. The responses after 10 minutes' ischaemia demonstrate the fall in threshold during the early stages of ischaemia described by Kugelberg (1944). It can be seen that after 30 minutes a rise in threshold had occurred but the action potential could not be restored to more than $70 \%$ of its maximal initial size in spite of a considerable increase in stimulus intensity. Thus the decrease in action potential size during ischaemia cannot be attributed merely to a rise in nerve threshold.

CARPal TUNNEL Patients The findings in 14 patients with the carpal tunnel syndrome may be compared with the results just described in control subjects. Both arms of one patient were examined, making a total of 15 tests for comparison. In all cases the diagnosis was made on the basis of characteristic clinical features. Their ages ranged from 37 to 69 years. Clinical summaries of the 14 patients are given by Fullerton (1962). In each patient a pneumatic cuff was inflated round the upper arm for 30 minutes unless the action potential following wrist stimulation fell to less than $25 \%$ of its initial size, at which stage the cuff was always released.

Wrist stimulation Fig. 6 shows the amplitude and area of the action potentials evoked by stimulation of the median nerve at the wrist during ischaemia in the carpal tunnel patients. As in the control subjects the results obtained by the two methods of measurement were similar. The effect of ischaemia was variable in these patients. By com- 

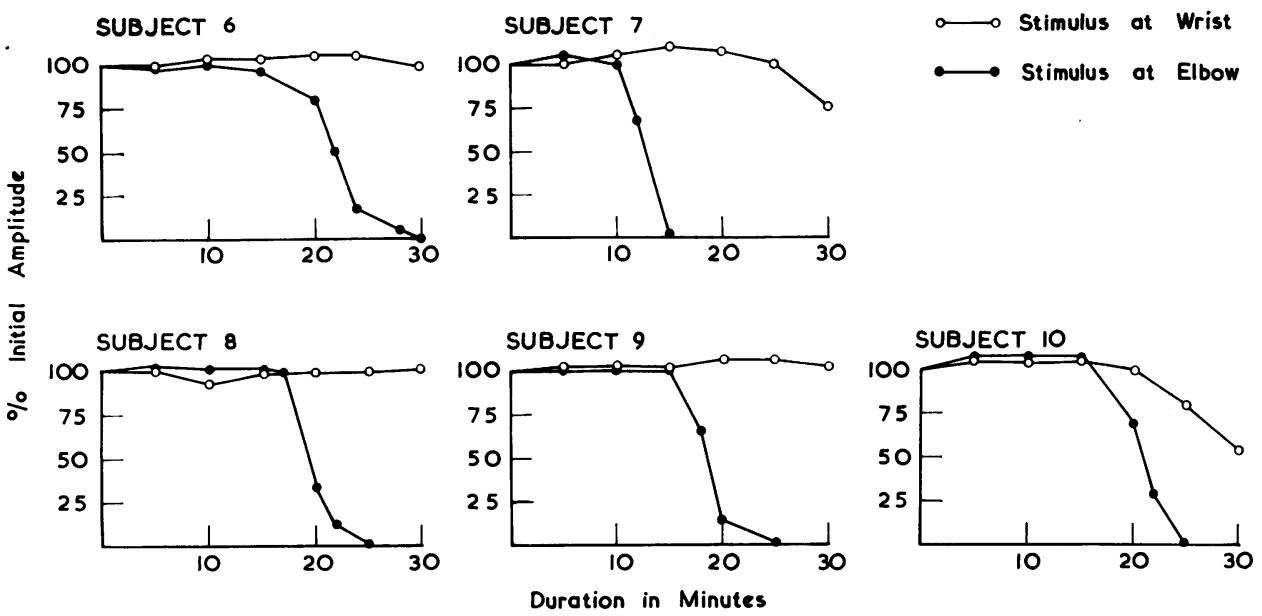

FIG. 4. Graphs showing the effects of 30 minutes' ischaemia on the amplitude of the thenar muscle action potentials in response to stimulation at wrist and elbow in five control subjects.



FIG. 5
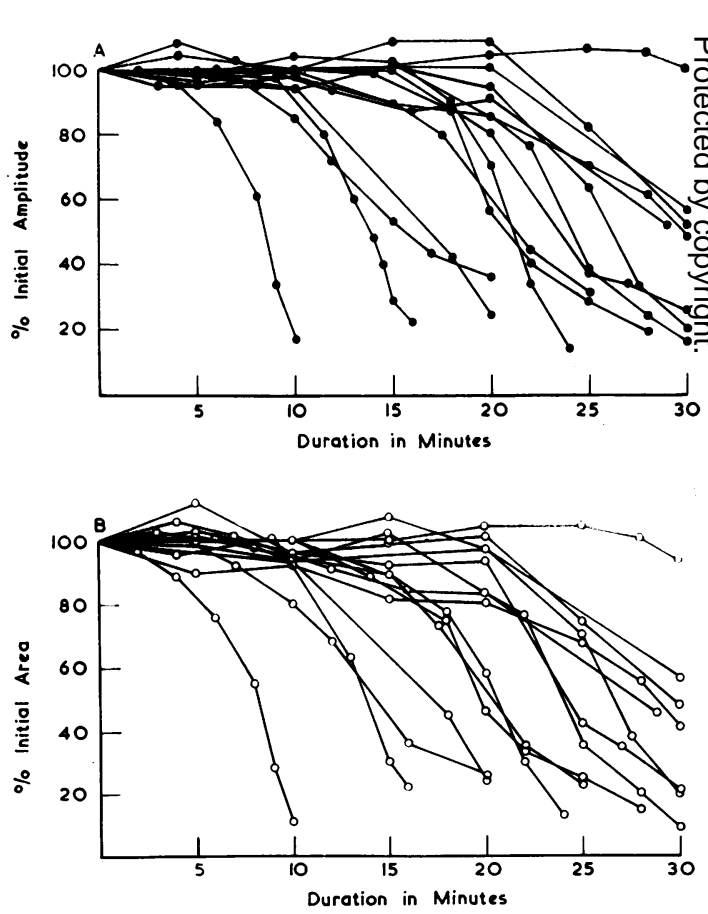

FIG. 6

FIG. 5. Graphs showing the effects of stimulus intensity on the area of the thenar muscle action potentials in one control subject and one carpal tunnel patient. Stimulation at wrist. Stimulus intensity is expressed in arbitrary units. The times shown on the graphs refer to the duration of ischaemia.

FIG. 6. Graphs showing the effects of ischaemia on the amplitude and area of the thenar muscle action potentials in 15 ก carpal tunnel patients. Stimulation at wrist. 

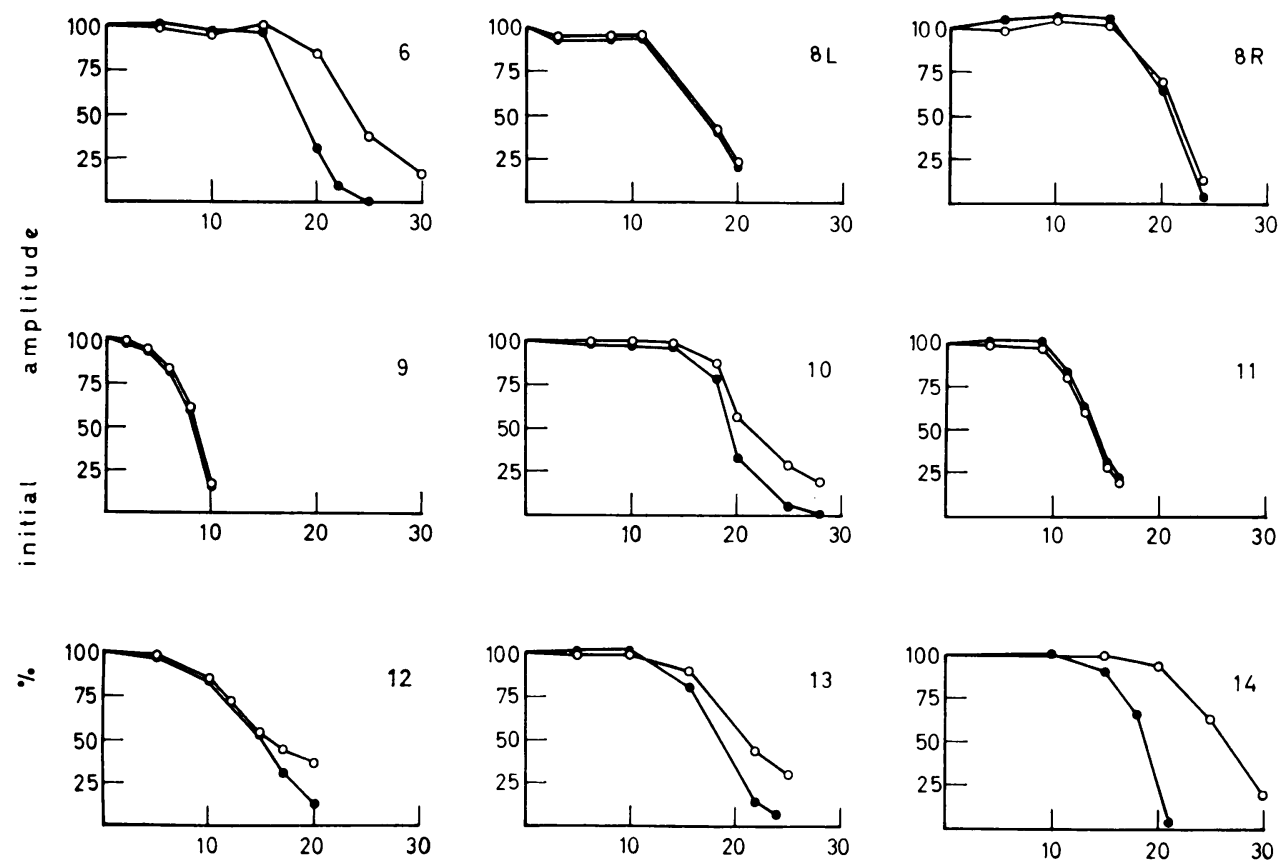

Duration in minutes

FIG. 7. Graphs showing the effects of ischaemia on the amplitude of the thenar muscle action potentials in nine carpal tunnel patients. The numbers in the upper right corners of the graphs are the case numbers of the carpal tunnel patients. Open circles denote wrist stimulation and closed circles elbow stimulation.

paring Figs. 2 and 6 it can be seen that in many cases the median nerves of the patients were more susceptible to ischaemia than those of the control subjects. In one patient the action potential had almost disappeared after 10 minutes' ischaemia and in six others it had fallen to less than $40 \%$ after 25 minutes. There were 10 patients in whom the action potential was less than $50 \%$ of its initial size after 30 minutes' ischaemia. Thus, in two-thirds of the patients tested, the median nerve showed an abnormal susceptibility to ischaemia.

Elbow stimulation Stimulation of the median nerve at both wrist and elbow was carried out in nine instances. The results are shown graphically in Fig. 7 and the photographic records obtained during one of these tests (case 9) are shown in Fig. 8. In four cases $(8 \mathrm{~L}, 8 \mathrm{R}, 9$, and 11$)$ the decrease in size of the action potential during ischaemia was the same following stimulation at wrist and elbow, indicating that failure of conduction occurred over the abnormal part of the nerve distal to the wrist electrode at a time when conduction in the forearm segment of the nerve was unaffected. This is in contrast to the behaviour of control subjects in whom the muscle action potential in response to a stimulus at the elbow was always reduced before that to a stimulus at the wrist (Fig. 4).

In the remaining five carpal tunnel patients tested by stimulation at both wrist and elbow the median nerve was less susceptible to ischaemia, and failure to conduction over the forearm segment of nerve was already occurring at a time when conduction became abnormal distal to the wrist (Fig. 7: cases 6, 10, 12, 13 , and 14).

Nerve fibre threshold The threshold of median nerve fibres is often raised at the wrist in patients with the carpal tunnel syndrome and it seemed possible that greater changes in threshold might occur during ischaemia in these patients than in control subjects. Figure $5 \mathrm{~b}$ shows stimulus intensity/ response curves from one patient during ischaemia. From this it can be seen that a local rise in nerve threshold was not responsible for the fall in action potential size.

Venous occlusion It could be suggested that increased tension under the flexor retinaculum due to venous congestion during inflation of the cuff might be responsible for the early failure of con- 

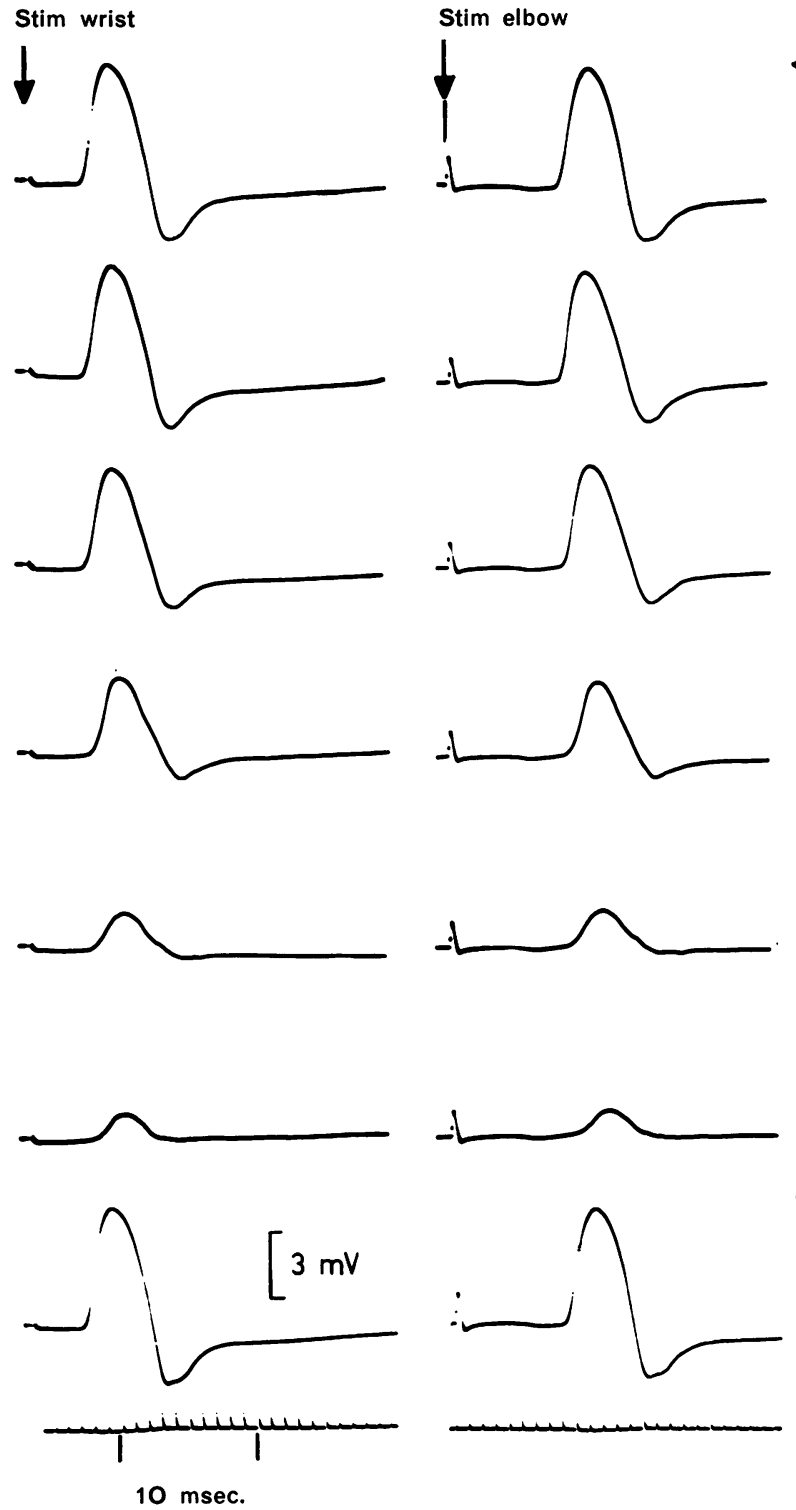

$6 \mathrm{~min}$.

$8 \mathrm{~min}$.

$9 \min$.

$10 \mathrm{~min}$.

FIG. 8. Case 9.

0 min. Carpal tunnel syndrome. Photographic records of the thenar muscle action potentials during and after ischaemia. Responses to wrist stimulation are shown on the left and

$4 \mathrm{~min}$ to elbow stimulation on the right.

$30 \mathrm{~min}$. duction in some carpal tunnel patients, even though the cuff was inflated as rapidly as possible. Two patients who had previously shown a rapid fall in action potential size during arterial occlusion were re-examined with the pneumatic cuff inflated to only $40 \mathrm{~mm}$. Hg. Although arterial occlusion produced a decrease in action potential size to about $25 \%$ of its initial value in both patients, venous occlusion for a similar period had no effect on the action potential. These results show that it was arterial arrest and not venous congestion which was responsible for the early failure of conduction.
EFFECT OF TEMPERATURE Desmedt (1958) has shown that action potential amplitude in response to nerve stimulation is constant over the temperature range from $37 \cdot 4$ to $21.0^{\circ} \mathrm{C}$., so that a fall in temperature cannot be responsible for the decrease in the action potential during ischaemia. Lewis, Pickering, and Rothschild (1931) found that sensory loss in the fingers during ischaemia developed a few minutes earlier at $35^{\circ} \mathrm{C}$. than at $25^{\circ} \mathrm{C}$. During the present study, however, the initial skin temperature was always between $34^{\circ}$ and $36^{\circ} \mathrm{C}$. and did not vary by more than $2^{\circ} \mathrm{C}$. during the period of arterial occlu- 
sion. Thus, variations in temperature are not likely to have affected the results.

\section{RECOVERY FROM ISCHAEMIA}

Previous workers have shown that muscle power and sensation recover rapidly following release of an arterial occluding cuff round the arm in normal subjects (Reid, 1928; Lewis et al., 1931). Recovery of nerve conduction was studied in a few cases to determine whether there were any differences between control subjects and carpal tunnel patients.

The size of the action potential after 30 minutes of return of normal circulation was taken as an index of recovery. The amplitudes of the action potentials evoked by stimulation of the median nerve at the wrist at the end of the ischaemic period and 30 minutes after release of the cuff are shown in Table I.

\section{TABLE I}

AMPLITUDE OF THENAR MUSCLE ACTION POTENTIALS AT END OF THE ISCHAEMIC PERIOD AND 30 MINUTES AFTER RETURN OF NORMAL CIRCULATION

\begin{tabular}{llll} 
Subject & $\begin{array}{l}\text { Duration of } \\
\text { Ischaemia } \\
\text { (min.) }\end{array}$ & $\begin{array}{l}\text { Amplitude at } \\
\text { End of } \\
\text { Ischaemia } \\
(\% \text { initial })\end{array}$ & $\begin{array}{l}\text { Amplitude after } \\
30 \text { Minutes } \\
\text { Recovery } \\
(\% \text { initial })\end{array}$ \\
\hline
\end{tabular}

\begin{tabular}{crrr}
\hline Controls & & & \\
7 & 30 & 75 & 99 \\
8 & 30 & 103 & 103 \\
9 & 30 & 103 & 100 \\
10 & 30 & 55 & 94 \\
& & & \\
\multicolumn{2}{l}{ Carpal tunnel patients } & 36 & 93 \\
12 & 20 & 31 & 100 \\
13 & 25 & 31 & 94 \\
14 & 30 & 20 &
\end{tabular}

It can be seen that, although there was a substantial fall in action potential amplitude in all three of the carpal tunnel patients, recovery appeared to be comparable to that of control subjects.

\section{EFFECTS OF ISCHAEMIA ON LATENCY}

In normal subjects conduction velocity becomes reduced during ischaemia (Magladery et al., 1950; Cobb and Marshall, 1954). In the present study changes in latency during ischaemia have been compared in control subjects and patients with the carpal tunnel syndrome.

CONTROL SUBJECTS At the end of 30 minutes' ischaemia the latency from stimulation of the median nerve at the wrist increased by 0.2 to 1.5 milliseconds above the initial value in the 10 control subjects (Table II). This represents an increase of from 7 to $38 \%$. Increases in latency were most marked in the subjects who showed the greatest decrease in action potential size.
TABLE II

AMPLITUDE AND LATENCY OF MUSCLE ACTION POTENTIAL AFTER 30 MINUTES' ISCHAEMIA IN 10 CONTROL SUBJECTS

\begin{tabular}{rrrr} 
Subject & $\begin{array}{l}\text { Amplitude } \\
\text { (\% initial) }\end{array}$ & $\begin{array}{l}\text { Increase in } \\
\text { Latency } \\
\text { (msec.) }\end{array}$ & $\begin{array}{l}\text { Latency } \\
\text { (\% initial) }\end{array}$ \\
\hline 1 & 71 & 1.0 & 133 \\
2 & 65 & 1.0 & 125 \\
3 & 103 & $0 \cdot 6$ & 119 \\
4 & 51 & 1.5 & 138 \\
5 & 79 & 0.6 & 125 \\
6 & 100 & 0.3 & 108 \\
7 & 75 & 0.9 & 136 \\
8 & 103 & 0.3 & 109 \\
9 & 103 & $0 \cdot 2$ & 107 \\
10 & 55 & 0.9 & 126
\end{tabular}

CARPAL TUNNEL PATIENTS In the 15 carpal tunnel patients the latency of the thenar muscle action potential with stimulation at the wrist increased by 0.6 to 3.4 milliseconds during the period of ischaemia. This represents an increase of from 9 to $68 \%$ (Table III). It can be seen from Table III that the percentage increase in latency at the end of the period of ischaemia was greater than that of control subjects in only three instances; in these three cases there had been a fall in both amplitude and area to less than $30 \%$ of the initial value.

TABLE III

AMPLITUDE AND LATENCY AT END OF ISCHAEMIC PERIOD FOR 15 CARPAL TUNNEL PATIENTS

\begin{tabular}{ccccc}
$\begin{array}{c}\text { Subject } \\
\text { Ischaemia } \\
\text { (min.) }\end{array}$ & $\begin{array}{l}\text { Amplitude } \\
\text { (\% initial) }\end{array}$ & $\begin{array}{l}\text { Increase in } \\
\text { Latency } \\
\text { (msec.) }\end{array}$ & $\begin{array}{l}\text { Latency } \\
\text { (\% initial) }\end{array}$ \\
\hline 1 & 29 & 54 & $1 \cdot 6$ & 126 \\
2 & 30 & 56 & $1 \cdot 5$ & 133 \\
3 & 30 & 26 & $1 \cdot 5$ & 127 \\
4 & 30 & 52 & $1 \cdot 0$ & 125 \\
5 & 30 & 100 & $1 \cdot 0$ & 111 \\
6 & 30 & 16 & $3 \cdot 4$ & 168 \\
7 & 30 & 48 & $0 \cdot 6$ & 109 \\
$8 \mathrm{~L}$ & 20 & 24 & $2 \cdot 3$ & 144 \\
$8 \mathrm{R}$ & 24 & 14 & $1 \cdot 2$ & 129 \\
9 & 10 & 17 & $1 \cdot 0$ & 124 \\
10 & 28 & 19 & $2 \cdot 1$ & 142 \\
11 & 16 & 22 & $0 \cdot 7$ & 115 \\
12 & 20 & 36 & $1 \cdot 0$ & 126 \\
13 & 25 & 31 & $1 \cdot 1$ & 127 \\
14 & 30 & 20 & $1 \cdot 3$ & 126
\end{tabular}

Change in temperature is known to affect conduction velocity. Carpendale (1956) found that the latency of the hypothenar muscle action potential produced by ulnar nerve stimulation at the wrist increased by 0.2 millisecond for each degree Centigrade fall in temperature. In the present study the fall in skin temperature over the thenar eminence varied between $1^{\circ}$ and $2^{\circ} \mathrm{C}$. during a 30-minute period of ischaemia. One might therefore expect an increase in latency of 0.2 to 0.4 millisecond due to 
fall in temperature. From Tables II and III it can be seen that the increase in latency was greater than this in nearly all cases.

\section{SUSCEPTIBILITY TO ISCHAEMIA IN \\ RELATION TO OTHER ABNORMALITIES IN THE CARPAL TUNNEL SYNDROME}

The severity of the median nerve lesions in patients with the carpal tunnel syndrome may be assessed in various ways, which are considered below in relation to the susceptibility of the nerve fibres to ischaemia. In order to make these correlations a quantitative assessment of the susceptibility to ischaemia was needed. The time at which the action potential amplitude or area had fallen to $60 \%$ of its initial size was chosen for this and will be designated in the following section as $\mathrm{T}(60 \% \mathrm{amp})$ and $\mathrm{T}(60 \%$ area $)$.

DURATION OF SYMPTOMS Patients can usually remember the time at which they first developed attacks of pain and paraesthesiae but the onset of muscle weakness and wasting is much less easily determined. The duration of symptoms is, therefore, especially difficult to determine in those patients who develop progressive thenar wasting as the most prominent feature of their syndrome and in whom attacks of pain and paraesthesiae are mild or absent. The length of history is thus no more than an approximate estimate of the duration of the disorder. In Table IV the duration of symptoms and susceptibility to ischaemia are shown for the carpal tunnel patients. It might be thought that susceptibility to ischaemia would be related to the length of time that the nerve had been subject to damage. Such a relation was not found, however. For example, two patients with very short histories, of only 10 days and five weeks (cases 12 and 9), showed a marked susceptibility to ischaemia and two with symptoms for many years (cases 1 and 5) were no more susceptible to ischaemia than control subjects. For the whole group there was no relation between susceptibility to ischaemia and duration of symptoms.

THENAR MUSCLE WASTING AND WEAKNESS In Table IV the degree of thenar muscle wasting and weakness is shown in relation to the other abnormalities in the carpal tunnel patients. It can be seen that the patients with gross wasting and weakness were not more susceptible to ischaemia than those without, and in fact the four patients whose nerves were most susceptible to ischaemia (cases $8 \mathrm{~L}, 9,11$, and 12) had no wasting or weakness.

AMPLITUDE OF THENAR MUSCLE ACTION POTENTIAL The proportion of muscle fibres of the thenar eminence that are supplied by the median nerve varies widely in normal subjects (Highet, 1943; Rowntree, 1949). There is thus considerable individual variation in the amplitude of the muscle action potential evoked by supramaximal stimulation of the median nerve. Reduction in the number of active motor units due to median nerve damage will resulf in a fall in amplitude, but since normal amplitude for a particular patient is not known, this measure? ment is a poor indication of the severity of the nerve lesion.

The amplitude of the thenar action potentiat before ischaemia in control subjects and in patients with the carpal tunnel syndrome is shown in Fig. 9. The range in control subjects was from 5.2 to 21.8 millivolts and in the carpal tunnel patients from 1.4 to $12 \cdot 1$ millivolts. Although there was considerable

TABLE IV

SUSCEPTIBILITY TO ISCHAEMIA IN RELATION TO OTHER ABNORMALITIES IN PATIENTS WITH THE CARPAL TUNNEL SYNDROME

\begin{tabular}{|c|c|c|c|c|c|c|c|}
\hline Subject & $\begin{array}{l}\text { Duration of } \\
\text { Symptoms }\end{array}$ & $\begin{array}{l}\text { Thenar Muscle } \\
\text { Wasting and } \\
\text { Weakness }\end{array}$ & $\begin{array}{l}\text { Severity of } \\
\text { Pain and } \\
\text { Paraesthesiae }\end{array}$ & $\begin{array}{l}\text { Latency from } \\
\text { Wrist } \\
\text { (msec.) }\end{array}$ & $\begin{array}{l}\text { Amplitude } \\
(m V)\end{array}$ & $\begin{array}{l}T(60 \% \\
A m p)(\min .)\end{array}$ & $\begin{array}{l}T(60 \% \\
\text { Area })(\min .\end{array}$ \\
\hline $\begin{array}{c}1 \\
2 \\
3 \\
4 \\
5 \\
6 \\
7 \\
8 \mathrm{~L} \\
8 \mathrm{R} \\
9 \\
10 \\
11 \\
12 \\
13 \\
14\end{array}$ & $\begin{array}{l}8 \mathrm{yr} . \\
1 \mathrm{yr} . \\
2 \mathrm{yr} . \\
9 \mathrm{mth} . \\
8 \mathrm{yr} . \\
1 \mathrm{yr} . \\
9 \mathrm{mth} . \\
4 \mathrm{mth} \text {. } \\
4 \mathrm{mth} . \\
5 \mathrm{wk} . \\
2 \mathrm{mth} . \\
6 \mathrm{yr} . \\
10 \mathrm{days} \\
4 \mathrm{mth} . \\
1 \mathrm{yr} .\end{array}$ & $\begin{array}{l}+++ \\
- \\
++ \\
+ \\
+ \\
++ \\
+ \\
- \\
- \\
- \\
- \\
- \\
- \\
+ \\
-\end{array}$ & $\begin{array}{l}+ \\
+ \\
+ \\
+ \\
- \\
+ \\
++ \\
+++ \\
++ \\
+++ \\
++ \\
+++ \\
+++ \\
++ \\
++\end{array}$ & $\begin{array}{l}6 \cdot 0 \\
4 \cdot 5 \\
5 \cdot 5 \\
4 \cdot 0 \\
8 \cdot 8 \\
5 \cdot 0 \\
6 \cdot 9 \\
5 \cdot 5 \\
4 \cdot 3 \\
4 \cdot 1 \\
5 \cdot 0 \\
4 \cdot 7 \\
3 \cdot 9 \\
4 \cdot 1 \\
4 \cdot 9\end{array}$ & $\begin{array}{r}2.4 \\
8 \cdot 6 \\
1 \cdot 4 \\
5 \cdot 3 \\
1 \cdot 6 \\
7 \cdot 5 \\
5 \cdot 6 \\
3 \cdot 6 \\
7 \cdot 5 \\
7 \cdot 9 \\
11 \cdot 2 \\
6 \cdot 0 \\
11 \cdot 6 \\
10.0 \\
12.1\end{array}$ & $\begin{array}{r}27 \\
29 \\
22 \\
29 \\
\infty \\
23 \\
28 \\
15 \\
21 \\
8 \\
20 \\
13 \\
14 \\
20 \\
25\end{array}$ & $\begin{array}{r}25 \\
29 \\
23 \\
28 \\
\infty \\
23 \\
27 \\
15 \\
20 \\
7 \\
19 \\
13 \\
13 \\
19 \\
26\end{array}$ \\
\hline
\end{tabular}

The degree of thenar muscle wasting and weakness was assessed as follows: $-=$ no wasting or weakness, $+=$ slight, $++=$ moderate, $++t=$ severe wasting and weakness. 


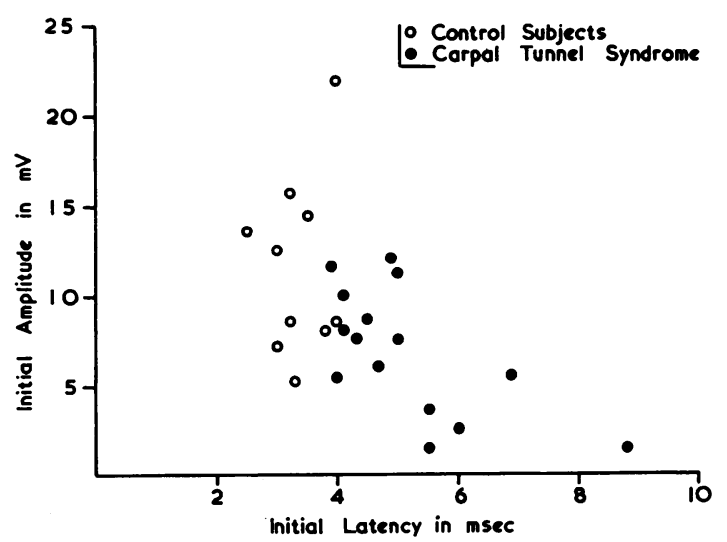

FIG. 9. Graph showing the amplitude and latency of the thenar muscle action potentials before ischaemia in control subjects and carpal tunnel patients. Stimulation at wrist.

overlap between the two groups the carpal tunnel patients were all at the lower end of the control range or below it, suggesting that in many there had been a reduction in the number of active motor units. The susceptibility to ischaemia and the amplitude of the thenar muscle action potential before ischaemia are shown in Table IV for the carpal tunnel patients. It can be seen that the patients with the smallest action potentials were not the most susceptible to ischaemia ; there was, in fact, no relation between the two.

LATENCY FROM THE WRIST One of the characteristic electrophysiological abnormalities in the carpal tunnel syndrome is an increase in latency of the muscle action potential in response to median nerve stimulation at the wrist (Simpson, 1956). Latencies in control subjects and carpal tunnel patients are shown in Fig. 9 from which it can be seen that all but two of the carpal tunnel patients had latencies longer than those of the controls. From Fig. 9 it can also be seen that there was some relation between increase in latency and decrease in amplitude, the patients with long latencies having responses of small amplitude.

Since the increase in latency provides some indication of the severity of nerve damage in the carpal tunnel syndrome, it might be thought that fibres with a long latency might be particularly susceptible to ischaemia. However, this was not so. Initial latency and susceptibility to ischaemia are shown in Table IV for the carpal tunnel patients, from which it can be seen that the cases with long latencies were not more susceptible to ischaemia than the others. This point was further illustrated by one patient in whom a gross dispersion of the



FIG. 10. Photographic records of the thenar muscle action potentials during ischaemia in a carpal tunnel patient.

units forming the muscle action potential was found (Fig. 10). The latency of the earliest motor units was 6 milliseconds, but there was a clearly recognizable group of motor units with a latency of 25 milliseconds. After 15 minutes' ischaemia the tracings showed failure of conduction in many short latency units with relatively little change in the potential formed by the long latency units. Thus, the fibres with short latency in this patient were more susceptible to ischaemia than those with a grossly prolonged latency.

It has been shown that nerve fibres giving rise to responses of long latency are not especially susceptible to ischaemia. It cannot be argued, however, that such nerve fibres are particularly resistant to ischaemia. In the case shown in Fig. 10, the motor units with the long latency of 25 milliseconds had ceased to conduct after 17 minutes' ischaemia, which is earlier than in some of the subjects in whom the motor units had much shorter latencies. Thus there seems to be no simple relation between the susceptibility of damaged nerve fibres to ischaemia and their conduction velocity.

SEVERITY AND FREQUENCY OF ATTACKS OF PAIN AND PARAESTHESIAE The most typical symptoms of the carpal tunnel syndrome are attacks of pain and paraesthesiae in the hand which occur particularly at night. The severity and frequency of attacks vary widely in different patients and in the same patient at different times. There are, however, a few patients who do not complain of this symptom but develop progressive weakness and wasting of the thenar muscles supplied by the median nerve, with or without sensory loss in the fingers. 
When patients were questioned about the number and severity of attacks of pain and paraesthesiae which they suffered in the days immediately preceding the test, it soon became apparent that those who were having very severe pain at frequent intervals showed a greatly increased susceptibility to ischaemia, and those who were tested at a time when they were having only mild or no attacks were not more susceptible than control subjects. Although it was difficult to make a quantitative assessment of the severity of symptoms, some grading was attempted on the basis of the patients' descriptions of their attacks as follows:-

$\mathbf{O}=$ free from attacks of pain and paraesthesiae,

$+=$ mild and infrequent attacks causing little disturbance of sleep, often consisting of attacks of paraesthesiae without pain

$++=$ more frequent attacks of pain and paraesthesiae with considerable disturbance of sleep and occasional mild symptoms by day

$+++=$ very frequent and severe attacks of pain and paraesthesiae occurring every night, seriously disturbing sleep, and with frequent attacks during the day as well as at night.

The relation between the symptoms at the time of the test and the susceptibility to ischaemia is shown in Table IV and Fig. 11. This relationship may also be illustrated by the following case histories.

Case 9 This patient had developed symptoms only five weeks previously but at the time of the test was having frequent attacks of pain and almost constant paraesthesiae, causing serious disturbance of sleep. There was no wasting or weakness of the thenar muscles and only mild subjective impairment of superficial sensation in the fingers of the left hand. The latency of

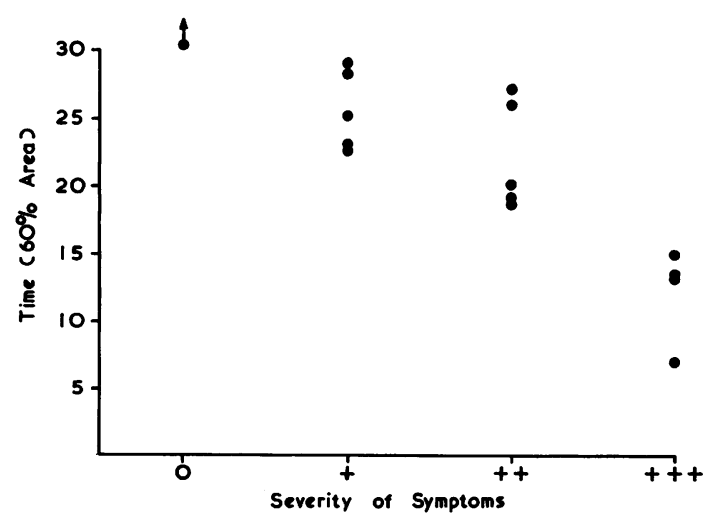

FIG. 11. Graph showing the relation between susceptibility to ischaemia and severity of attacks of pain and paraesthesiae in the days immediately preceding the ischaemia test. The criteria for grading symptoms are described in the text. the muscle action potential following median nerve $\underset{\mathbb{D}}{Z}$ stimulation at the wrist was 4.1 milliseconds and the action potential amplitude was 7.9 millivolts. The effect of of ischaemia is shown in Fig. 8, from which it can be seen that the action potentials in response to stimulation at both wrist and elbow had almost disappeared after 10 minutes' ischaemia.

The distal segment of the median nerve of this $\stackrel{2}{2}$ patient with severe pain and paraesthesiae showed a

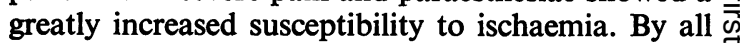
other criteria, however, the median nerve lesion was mild.

Case 5 This patient may be contrasted with the one just mentioned. She had suffered mild attacks of pain and paraesthesiae in the hands for eight years but at the time os of the test had been symptom-free for six weeks. Examina- $\vec{\circ}$ tion revealed slight wasting and weakness of the thenar muscles and some impairment of sensation in the fingers. $\vec{\omega}$ The latency of the thenar action potential following wrist $\stackrel{S}{S}$ stimulation was markedly prolonged (8.8 milliseconds) and the action potential amplitude was below the control 0 range (1.6 millivolts). The action potential evoked by N median nerve stimulation at the wrist was unaffected by $\mathcal{G}$ 30 minutes' ischaemia.

Although the history was long, and although latency and amplitude measurements indicated coe siderable median nerve damage at the wrist, the $O$ patient had been free of pain and paraesthesiae for $\frac{9}{0}$ several weeks at the time of testing and 30 minutes ischaemia had no effect on the size of the action. potential.

Case 8 This patient had suffered frequent and severe attacks of pain and paraesthesiae in both hands for four months before the ischaemia test. The symptoms on the left were worse than those on the right. On examination there was no motor impairment in either hand. Sensation $\frac{O}{8}$

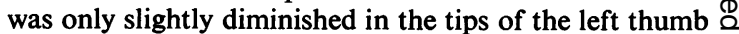
and index finger and was normal in the right hand. The $\overrightarrow{\vec{P}}$ latency of the thenar muscle action potential following wrist stimulation was 5.5 milliseconds on the left and 4.3 milliseconds on the right. The amplitude of the muscle action potential was 3.6 millivolts on the left and 7.5 millivolts on the right.

At a time when her symptoms were severe both arms were examined. The amplitude of the muscle action potential on the left was reduced to $24 \%$ of its initial size after 20 minutes' ischaemia. There was an increased $\delta$ susceptibility to ischaemia on the right also, the amplitude of the action potential falling to $14 \%$ of its initial size after 24 minutes' ischaemia.

She was admitted to hospital for surgical division of $D$ the left flexor retinaculum, which was carried out by Mr. V. Logue, with immediate relief of her symptoms. N During rest in hospital the symptoms on the right also subsided and after being in hospital for a week she had $N$ no symptoms in this hand either. The right arm was re- N examined at this time. After 30 minutes' ischaemia the 


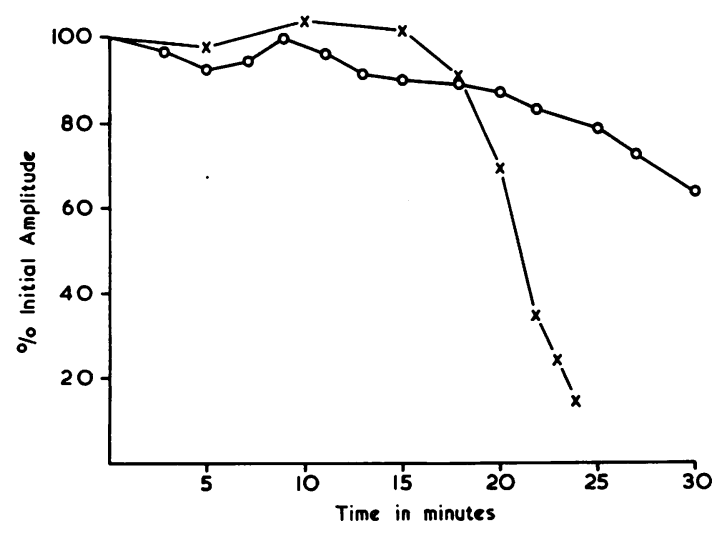

FIG. 12. Graph showing the results of two tests on the right median nerve of one carpal tunnel patient. Stimulation at wrist.

$\mathrm{X}=$ during acute symptoms

$\mathrm{O}=$ after one week's bed rest

amplitude of the action potential had only fallen to $64 \%$ of its initial size. Fig. 12 shows the effect of ischaemia on the amplitude of the action potential following stimulation of the right median nerve at the wrist during the time when her symptoms were severe and after rest in bed when the symptoms had subsided.

The tests on this patient demonstrate that during a period of acute symptoms the median nerve was abnormally susceptible to ischaemia, but when the patient was free from pain and paraesthesiae the nerve was not more susceptible to ischaemia than that of some control subjects.

\section{DISCUSSION}

The view that intermittent ischaemia of the median nerve at the wrist plays a part in the development of symptoms in patients with the carpal tunnel syndrome has been strengthened by the observations of Gilliatt and Wilson (1953) that some patients rapidly develop symptoms similar to those of their spontaneous attacks during arterial arrest. Both the studies described by Gilliatt and Wilson (1953, 1954) and those reported in the present work have shown that the median nerve of many patients with the carpal tunnel syndrome is abnormally susceptible to ischaemia. Gilliatt and Wilson demonstrated that the intense pain and paraesthesiae occurring in some patients after inflating a pneumatic cuff arose in the segment of median nerve distal to the wrist. In the present study abnormally rapid failure of motor conduction during ischaemia has also been shown to develop in the distal part of the median nerve. Gilliatt and Wilson noted that the patients who developed severe symptoms after inflation of a pneumatic cuff were those having frequent spontaneous attacks at the time of the test. In the present series the striking association between the severity and frequency of patients' attacks of pain and paraesthesiae in the days immediately preceding the test and the time at which motor nerve conduction failed during induced ischaemia has already been described. Observations made by Barlow and Pochin (1948) may be of some importance in interpreting these findings. They showed that after a 30-minute period of ischaemia voluntary power appeared to recover fully within 10 minutes but that paralysis occurred earlier during a second period of ischaemia if this was produced within six hours of the first. It seems possible that a similar effect could account for the increased susceptibility of the median nerve to induced ischaemia in patients who were having frequent spontaneous 'ischaemic' attacks accompanied by pain and paraesthesia and reversible sensory loss.

There thus seems to be good evidence that the intermittent symptoms in the carpal tunnel syndrome are due to ischaemia. However, can the more permanent changes such as increase in latency also be attributed to ischaemia? The effects of short episodes of ischaemia have been shown to be rapidly reversible by Lewis et al. (1931), Barlow and Pochin (1948), and Gelfan and Tarlov (1956); furthermore, there was no evidence of delayed recovery of motor nerve conduction following a period of ischaemia in the present study. It has been previously suggested (Simpson, 1956) that the increase in latency in the distal segment of the median nerve might be due to partial ischaemia of the fibres under the flexor retinaculum. However, there is now considerable evidence suggesting that this is not so. For example, increase in latency during induced ischaemia was of the same order in patients with the carpal tunnel syndrome as in control subjects. In no patient or control subject did the latency increase to more than twice its initial value. It is well known that in some patients with the carpal tunnel syndrome latencies of up to 10 times normal may be seen. These are very much longer latencies than can be accounted for by the effect of ischaemia alone.

If fibres with long latencies were already partially ischaemic one might expect these fibres to be most susceptible to further ischaemia. However, this was not found. In fact, there was a tendency for the patients with short latency responses to be most susceptible to ischaemia (Table IV). These findings were probably related to the differing ways in which symptoms developed in individual patients. Those with the most severe pain were most susceptible to ischaemia. They usually had a short history and 
consulted a doctor early because of the severity of their symptoms. When the history was short the latency was usually found to be within the normal range. Those with prolonged latency usually had a long history, but because their symptoms were less obtrusive they had not been referred for treatment earlier. A few patients who had both a long latency and severe symptoms did show an increased susceptibility to ischaemia (e.g., Fig. 10). Since patients with a prolonged latency do not necessarily show an increased susceptibility to induced ischaemia and patients having frequent and severe spontaneous 'ischaemic' attacks do not necessarily have a prolonged latency, it seems unlikely that slowing of conduction sufficient to cause the increase in latency could be due to chronic partial ischaemia of the nerve fibres.

One possible explanation for the slowing of conduction would be that repeated attacks of ischaemia destroy the larger fibres in the nerve trunk leaving only the smaller fibres capable of conducting impulses. There is some evidence from the work of Garven, Gairns, and Smith (1962) on diameter of nerve fibre in arteriosclerotic limbs that long-continued ischaemia does have the effect of eliminating large fibres to a greater extent than small ones. However, if the nerve supply to intrafusal muscle fibres is ignored, it is known that the difference in conduction velocity between the fastest and slowest motor fibres supplying the small muscles of the hand is not more than $40 \%$ (Thomas, Sears, and Gilliatt, 1959). Thus, disappearance of the fastest fibres could only be expected to produce a small increase in latency and certainly could not account for the very large increases sometimes seen in the carpal tunnel syndrome. It might be suggested that fibres undergo Wallerian degeneration as a result of a severe attack of ischaemia and are then able to regenerate, the long latencies being due to conduction in regenerating fibres. This would be in keeping with the results of animal experiments from which it is known that in the early stages of regeneration conduction velocity may be reduced to $5 \%$ of normal (Berry, Grundfest, and Hinsey, 1944; Sanders and Whitteridge, 1946). It was argued by Goodman and Gilliatt (1961), however, that prolonged latency in the carpal tunnel syndrome was unlikely to be due to conduction in regenerating fibres as it often remained unchanged in repeated examinations over many months in the absence of treatment.

A more probable explanation for the slowing of conduction is that put forward by Thomas (1960), on the basis of animal experiments by Weiss and Hiscoe (1948), who found that when a constricting sleeve was applied round normal rat nerves, the fibres became thinned both at the site of constriction and to a lesser extent distal to the constriction. These changes affected both axis cylinders and myelin sheaths. Duncan (1948) found similar changes after $\widehat{\theta}$ ligatures had been placed round the sciatic nerves of ${ }_{0}$ young rats, thereby producing pressure as the animals grew. Thus, it seems possible that chronic $\stackrel{?}{\mathrm{O}}$ compression of the median nerve under the flexor retinaculum might be responsible for a reduction of fibre diameter and an associated increase in latency. Few anatomical studies on the median nerve in the carpal tunnel syndrome are available, but in a recent case reduction of fibre diameter has been found under the flexor retinaculum and to a lesser extent in digital nerve fibres distal to the lesion (Thomas and Fullerton, 1963).

From the arguments detailed above it may be suggested that there are two processes concerned in the carpal tunnel syndrome, one being ischaemia occurring in attacks which cause pain, paraesthesiae, and transient weakness with reversible failure of nerve conduction, and the other direct pressure pro- N ducing a slow change in the nerve fibres with or reduction of fibre diameter and increase in latencys $\omega_{\infty}$ This concept would explain the dissociation fret of quently observed between motor latency anf susceptibility to ischaemia. While this dissociation may be seen at any time during the course of the disease it is particularly obvious following surgica 0 division of the retinaculum. Attacks of pain ar immediately relieved by operation, whereas thêे recovery of conduction velocity is a slow and pro gressive change, sometimes taking as long as 18 months after operation in severe cases (Goodman and Gilliatt, 1961). In this respect it is interesting that in one patient reported by Goodman and Gilliatt (1961) treatment by splinting abolished the attacks of pain and paraesthesiae and yet at the same time the latency of the sensory action potential recorded at the wrist following stimulation of digital nerve fibres increased.

In the majority of patients both ischaemia and direct pressure appear to contribute to the abnormality of nerve function. However, it may be postulated that in some cases one of these factors is predominant. For example, a few patients have attacks of pain and paraesthesiae for many years without developing permanent thenar muscle wasting or weakness, sensory loss in the fingers, or abnormality of conduction velocity. It may be suggested that this type of lesion is ischaemic. By contrast there are patients who develop progressive and severe muscle wasting with grossly prolonged latency who have never had attacks of pain and paraesthesiae. This type of lesion may be due to direct pressure on the nerve. 


\section{SUMMARY}

The effect of ischaemia on conduction in motor fibres of the median nerve has been studied in control subjects and patients with a clinical diagnosis of the carpal tunnel syndrome. Ischaemia was produced by inflating a pneumatic cuff round the upper arm to above arterial pressure and the median nerve was stimulated at two or five-minute intervals below the cuff. The action potential of the thenar muscles was recorded through surface electrodes.

In two-thirds of the carpal tunnel patients the amplitude and area of the muscle action potential decreased more rapidly during ischaemia than in the control subjects. In some patients this effect was shown to be due to a block in conduction confined to the segment of the median nerve below the wrist. It was established that decrease in action potential size was not due to changes in nerve threshold, to venous congestion, or to a fall in temperature. Recovery occurred rapidly after release of the cuff in both patients and control subjects.

Differences between control subjects and patients were less marked when changes in latency during ischaemia were compared. Some increase which could not be attributed to a fall in temperature occurred in both groups.

It has been shown that susceptibility to ischaemia in the carpal tunnel patients was not related to the duration of symptoms, degree of muscle wasting and weakness or to the latency of the muscle response following wrist stimulation; it was, however, closely related to the severity of pain and paraesthesiae in the days preceding the test.

On the basis of these findings it is suggested that two mechanisms may be responsible for the abnormalities in the carpal tunnel syndrome, one being a rapidly reversible change in the nerve fibres associated with ischaemic attacks and the other a slowly developing structural change in the fibres resulting from pressure on the nerve under the flexor retinaculum.

I would like to thank Professor R. W. Gilliatt for his helpful criticism and advice; the physicians of the National Hospitals for Nervous Diseases and the Middlesex Hospital for referring patients. I am also indebted to Mr. H. B. Morton for building the electronic integrator, and the Department of Applied Electrophysiology, the National Hospitals, and the Clinical Research Committee of the Middlesex Hospital for providing facilities.

\section{REFERENCES}

Barlow, E. D., and Pochin, E. E. (1948). Clin. Sci., 6, 303.

Berry, C. M., Grundfest, H., and Hinsey, J. C. (1944). J. Neurophysiol., 7, 103.

Brain, W. R., Wright, A. D., and Wilkinson, M. (1947). Lancet, 1, 277.

Carpendale, M. T. F. (1956). M.S. (Phys. Med.) Thesis, University of Minnesota.

Cobb, W., and Marshall, J. (1954). J. Neurol. Neurosurg. Psychiat., 17, 183 .

Desmedt, J. E. (1958). Acta neurol. belg., 58, 977.

Duncan, D. (1948). J. Neuropath. exp. Neurol., 7, 261.

Fullerton, P. M. (1962). D.M. Thesis, Oxford University.

Garven, H. S. D., Gairns, F. W., and Smith, G. (1962). Scot. med. J., $7,250$.

Gelfan, S., and Tarlov, I. M. (1956). Amer. J. Physiol., 185, 217.

Gilliatt, R. W., and Sears, T. A. (1958). J. Neurol. Neurosurg. Psychiat., 21, 109.

- and Wilson, T. G. (1953). Lancet, 2, 595.

,--1 (1954). J. Neurol. Neurosurg. Psychiat., 17, 104.

Goodman, H. V., and Gilliatt, R. W. (1961). Ann. phys. Med., 6, 137.

Highet, W. B. (1943). Lancet. 1, 227.

Kendall, D. (1960). Brit. med. J., 2, 1633.

Kremer, M., Gilliatt, R. W., Golding, J. S. R., and Wilson, T. G. (1953). Lancet, 2, 590.

Kugelberg, E. (1944). Acta physiol. Scand., 8, suppl. 24.

Lewis, T., Pickering, G. W., and Rothschild, P. (1931). Heart, 16, 1.

Magladery, J. W., McDougal, D. B., and Stoll, J. (1950). Johns Hopk. Hosp. Bull., 86, 291.

Reid, C. (1928). Quart. J. exp. Physiol., 19, 127.

Rowntree, T. (1949). J. Bone Jt Surg., 31B, 505.

Sanders, F. K., and Whitteridge, D. (1946). J. Physiol. (Lond.), 105, 152.

Simpson, J. A. (1956). J. Neurol. Neurosurg. Psychiat., 19, 275.

Thomas, P. K. (1960). Neurology, 10, 1045.

-

-, Sears, T. A., and Gilliatt, R. W. (1959). J. Neurol. Neurosurg. Psychiat., 22, 175.

Weiss, P., and Hiscoe, H. B. (1948). J. exp. Zool., 107, 315. 